\title{
TEACHING STRATEGIES FOR LECTURERS AND TUTORS TO ASSIST NON-ENGLISH MOTHER TONGUE TERTIARY STUDENTS: SUMMARISING, PARAPHRASING AND VOCABULARY ENRICHMENT
}

\author{
J. L. Coullie \\ University of KwaZulu-Natal, Howard College, and \\ Academic Skills Centre, University of Canterbury \\ New Zealand \\ e-mail: judith.coullie@canterbury.ac.nz
}

\section{ABSTRACT}

Given the increasingly globalised nature of tertiary education and the growth of English as a second or other language, high numbers of international students studying at English medium tertiary institutions have English as a second (L2) or additional language (EAL). But few efforts may be made to accommodate such students who report that the main difficulty relates to proficiency in English language, and that this results in greater stress and anxiety (Andrade 2006). The key skills of summarising and paraphrasing are reliant upon understanding of concepts and information, in written and oral forms. How can essential content be covered in lectures and tutorials so as to include assistance for non-native speakers of English? I consider a range of pedagogical strategies that can be adopted by university lecturers and tutors to enable EAL students to summarise and paraphrase effectively so as to demonstrate mastery of disciplinespecific vocabulary.

Keywords: non-English students, summarising, paraphrasing, lectures, tutorials, teaching strategies

The global spread of English as a second or other language continues, leading to some rather extreme practices in certain non-English countries (Pennycook 2017; Motha and Lin 2014). English remains the dominant language of e-communication (Casanave 2004, 215), despite the decreasing proportion of English content on the Web (from $82.3 \%$ in 1997 to $56.4 \%$ in 2002; Lobachev 2008). It is known as "the lingua franca of the scientific community" (Van Weijen 2012, n.p.) and retains its pre-eminence in academic publishing (Thomson 2017): in 2015, in countries like Germany, France, and Spain, English-language academic papers outnumber publications in the country's own language several times over (Huttner-Koros 2015). This is partly because researchers who want their work to achieve prominence are drawn to publish in English: on SCImago, all of the top 50 journals are published in English and originate from either the U.S. or the U.K. (Huttner-Koros 2015). 
The predominance of English affects teaching in universities and schools: post-apartheid South Africa, for instance, has eleven official languages, yet, "Due to the perceived instrumental value of English, many local schools rejected indigenous languages as medium of instruction in favour of English" (Van Wyk 2014, 205; see also Uys et al. 2007, 69). Dearden notes that in 55 non-anglophone countries, there is a rapidly growing trend for tertiary institutions to adopt English as the medium of instruction (Dearden 2014, 4; 16). And students from around the world choose to study in English-speaking countries, across a wide range of subject areas. In the USA, for instance, Rao notes that the percentage of international students has increased by almost 31 per cent since 2002 (2017, 1000). The increasingly globalised nature of tertiary education, and the strong emphasis on education as a source of foreign income (Rao $2017,1001)$, means that high numbers of students studying at English medium universities have a mother tongue which is not English. For instance, at the University of Canterbury, in New Zealand, around 65 per cent of doctoral students are non-New Zealanders; many do not have English as their first language.

Whether English is a second language (L2) or an additional or foreign language (EAL/EFL), university students are required to understand a great deal of conceptually and linguistically complex material and reach the same high standard of English fluency and proficiency in their written work as native speakers of English. Students in most disciplines will need to master not only the specific discursive norms of the discipline (or disciplines, if they are undergraduates in general degree programmes) but achieve a high standard of formality, grammatical correctness and control of specialised and non-specialised vocabulary in their written work. Students are required to synthesise ideas from source materials; this depends on them comprehending key concepts and arguments, and connecting these by means of summary, paraphrase and quotation for particular purposes in their writing. Thompson, Morton and Storch cite many studies that show that it is difficult for L2 students to employ these "linguistic and authorial intertextual manipulations" (2013, 99; see also Hirvela and Du 2013, 87; Kirkland and Saunders 1991) and to use specialised language and discursive features in "rhetorically appropriate and authoritative ways" (Thompson, Morton and Storch 2013, 101). In a wideranging review of studies focusing on international students, Andrade $(2006,135)$ notes that a significant proportion found that international students exhibit more stress and anxiety and that the main difficulty relates to proficiency in English language.

Academic writing requires writers to engage with relevant scholarship; this means writers draw on significant findings and ideas, with little direct quotation, to support their viewpoint. Summarising and paraphrasing are key skills, skills which academics may tend to assume students will master along the way - and which thus do not have to be taught. Furthermore, in 
the process of ensuring that subject content is covered, little thought may be given to the magnification of difficulties for EAL students. In several studies in which views of international students were canvassed, students "identified English-related skills, such as listening ability, lecture and reading comprehension, note taking, oral communication, vocabulary and writing, as being problematic" (Andrade 2006, 139). ${ }^{1}$ How can university teachers assist non-native speakers of English to manage sophisticated concepts and specialised academic terminology? In this article I consider some strategies that can be adopted by lecturers and tutors in contentfocused classes to assist non-native users of English acquire the fundamental academic citation skills as they assimilate critical vocabulary.

Lecturers and tutors, as experts in the discipline, endeavour to teach students the concepts, methods, skills and discursive approaches of the subject. Formal teaching usually seeks to engender a combination of responses from students: listening and taking notes, understanding, questioning, and performing tasks. The goal of such teaching is to promote the learning that students will need to demonstrate so that they may receive public endorsement in the form of a qualification. The Oxford English Dictionary defines teaching as the "imparting of instruction or knowledge"; learning is defined as "the action of receiving instruction or acquiring knowledge". 2 Of course, learning occurs both within and beyond the confines of formal teaching situations; however, in formal educational settings, although extra-mural learning is encouraged and perhaps even expected, teaching in lectures and tutorials is held to be key to directing, shaping and (of particular importance to governments and the broader society) assessing learning. And while teaching in lectures and tutorials does not equate to - or even assure - learning, it has long been deemed to be the most efficacious way that tertiary institutions can foster targeted learning.

This article argues in favour of the adoption of teaching methods in content-directed lectures and tutorials which aim to assist L2 students to learn the language of the discipline being taught. This argument is premised on the assumption that while teaching by lecturers and tutors is no guarantee of learning in students, it is nonetheless, in part, the responsibility of teachers/lecturers to employ strategies which will enrich students' language skills whilst content is taught (Uys et al. 2007). As Benjamin Whorf(1956) found almost a century ago, "the structure of a human being's language influences the manner in which he [or she] understands reality and behaves with respect to it" (Carroll 1956, 23). Comprehending the particular segment of "reality" which a subject explores, its subject-specific conceptual paradigm, requires the appropriate language; articulating ideas in writing depends upon discursive competence. I outline a range of approaches that can be incorporated into lectures and/or tutorials. ${ }^{3}$ Students are not passive recipients of information and skills; learning requires 
engagement. In this article I survey a range of strategies which lecturers and tutors may assess so as to improve the potential for engaged learning by students, for increased understanding. The important question is not "Which way of assisting students to gain these skills is best?", but "How can the various ways of learning be used to help each other and provide optimal learning?" (Waring and Nation 2004, 107). As Dearden notes, "at the very least it is encumbent on researchers and teachers alike to strive to make the experience for their learners as enabling and as rewarding as possible" $(2014,33)$.

Good teachers are always learning: in this article I offer a number of approaches which may enrich lecturers' and tutors' knowledge about teaching. Given the pressures to conduct research, publish and perform administrative duties, academics may be hard pressed to devote time to improving teaching methods. However, if high dropout rates of first year students are an indication, students are under pressure too. In New Zealand, for example, the attrition of first year students is slightly more than 20 per cent (Tertiary Education Commission, 2017). In South Africa, the figure is closer to 40 per cent (EduLoan, 2009; Gumede, 2017). The many contributing causes may include students' prior academic achievement, age, gender, class, ethnicity, degree programme and part-time or full-time study (Pather, 2015; Jia and Maloney, 2015) as well as ineffective teaching, poor support systems and lack of access to resources. Causal complexity notwithstanding, pedagogy is important and it as well to educate students more effectively wherever, and to the greatest extent, possible.

Typically (and traditionally), lecturing involves the sage on the stage talking for 50 minutes; aspects of the lecture are then covered in more learner-focused activities in tutorials. I am proposing explicitly learner focused pedagogical elements in lectures and tutorials, with scaffolding of both subject content and skills, taking into account the imbrications of receptive skills (listening and reading) with productive language skills (note-taking, speaking and writing), with a view to ensuring that the needs of L2 students are intentionally and meaningfully addressed.

Key to effective teaching is educators' awareness of exactly what it is that they require students to learn, understand and $d o$, the latter to ensure that the skills can, at least to some extent, be built into content teaching. If teachers do not consider the range of skills demanded of students, universities will continue along well-worn paths of content delivery (usually on the misguided assumption that students will simply absorb the information and skills) in educational contexts and with student cohorts which are far from traditional.

Generally, course outlines list learning outcomes for entire modules and advertise learning objectives for content as well as skills. ${ }^{4}$ But typically, the focus of lectures is on content; skills such as critical reading, effective use of source material and greater discursive competency are 
expected to be acquired incidentally. These skills are often built into design of assessments but seldom into the design of teaching programmes. I suggest that lecturers and tutors inform students of the skills which they will need - learning is more likely to occur when learning objectives are known (Denton et al. 2012, 48-9) - and incorporate appropriate strategies into content-focused classes.

\section{SUMMARISING AND PARAPHRASING}

Early in their studies, students need to understand that research-based writing requires that the writer enter a conversation, using existing knowledge to construct an interpretation or argument (Dartmouth Institute, 2017), using (to varying degrees, depending on the discipline and type of document) the pyramid of quotation, paraphrase and summary (Figure 1).

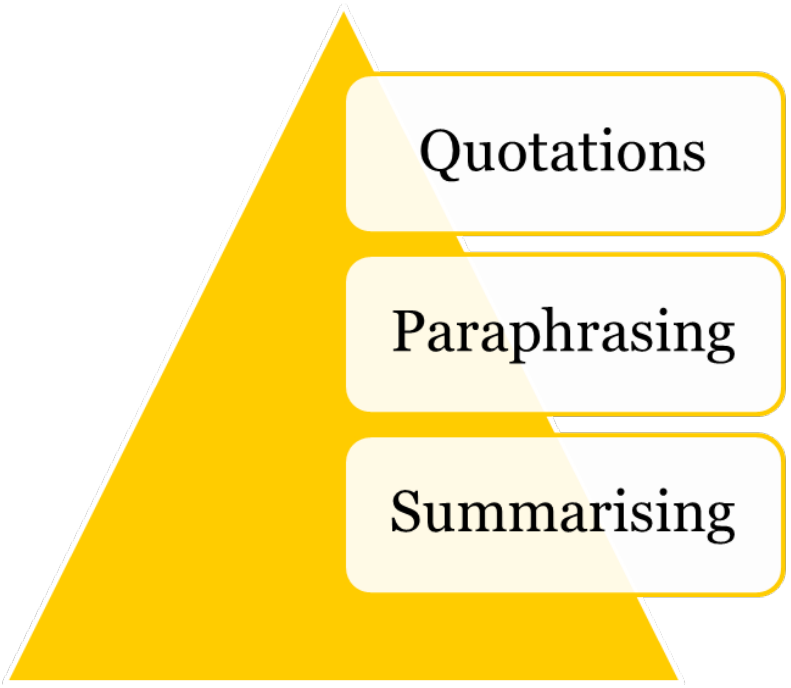

Figure 1: Relative proportions of quoting paraphrasing and summarising

If this interweaving of others' ideas with the students' own is made explicit, discussions about the hierarchy of citation methods can lead to broader discussions about the importance of honesty which might help students to avoid plagiarism (Keck 2006). Greasley asserts that "Copying and pasting is the zeitgeist of the times" $(2011,113)$. If this is true for students in general, how much more tempting must copying and pasting be for those students whose cultural backgrounds advocate a subservient and uncritical acceptance of expert sources or who simply lack confidence in their English competency? Instead of relying on warnings of the dire consequences for plagiarists, university teachers need to show students how they can go beyond parroting, and why this will be of benefit to them.

Ensuring that students are informed about what they need to learn and why is vital since 
learning occurs most effectively when there is commitment on the part of the learner. Attention to student motivation regarding responsible and meaningful engagement with published research should be a discernible feature of classroom interactions, with extended attention to this probably being covered most effectively in small group situations. Approaches should be flexible, doing "justice to the idiosyncrasies of personal meaning-making in social context" (Ushioda 2009, 219). Ideally, activities which raise the issue of motivation - and which aim to raise motivation levels - would occur both before and during the teaching of summarising and paraphrasing strategies so that students are stimulated to invest time and energy into mastery of these skills. Several levels of motivation might be involved for L2 students: a desire to be fluent in English-medium academic discourses ${ }^{5}$, to learn the specific skills of summarising and paraphrasing, and to master the associated conceptual/cognitive competences - motivation which goes beyond simply recognising that summarising and paraphrasing are important to academic success but are rather appreciated as steps in the process to achieving what Dörnyei refers to as the "ought-to self" $(2009,353)$. Summarising and paraphrasing require a sound grasp of the source material; the alternatives - quoting or cutting and pasting - require far less comprehension. The link between comprehension and these conventions should be accorded particular consideration, either in discussion or debates, in informal online posts, or in more formal submissions. Questions for deliberation might include: why is it important that students/researchers understand sources they are citing? What do you as a student want to learn, what do you want to become? When you graduate, would you expect to have the knowledge the certificate implies? How might employers feel if they employed graduates who did not have the skills apparently guaranteed by the degree certificates? Such debate requires students to think about why the understanding required for effective summarising and paraphrasing is important for them as future graduates and for the broader society. Dörnyei and Ushioda include several empirical studies ${ }^{6}$ in their edited collection whose "results [...] supported the claim that future self-guides are potent motivators" $(2009,351)$. It is argued that teachers need to engage students as whole persons, people with lives beyond the classroom environment (Ushioda 2009, 223), "[taking] into account sufficiently the process-oriented nature of motivation or the dynamic interaction between motivation and the social environment" (Dörnyei and Ushioda $2009,354)$.

\section{SUMMARISING STRATEGIES}

Effective summarising hinges on comprehension and the ability to distinguish between main points and then to express such ideas concisely in what are mostly the writer's own words (Hedgcock and Ferris 2009, cited in Hirvela and Du 2013, 88). Because of the complexity of 
this recursive process (Kirkland and Saunders 1991, 105-106), summarising is not a skill that will come readily to L2 students. Ideally, students should be given - and afforded low risk opportunities to practise - strategies for summarising. For instance, they can be advised to underline topic sentences, colour code elements of text, or create diagrams (Kirkland and Saunders 1991, 115) and given the strategies below for summarising pre-class (lecture or tutorial) readings.

1. Six step method: 1. List main idea for each paragraph; 2. Underline main idea statements; 3. Combine any ideas that could go together; 4 . Number ideas in logical order; 5 . Write summary in one paragraph; 6. Edit paragraph (Denton et al. 2012, 125).

2. Students can be provided with templates or programs (https://www.mindmeister.com/ is one example) for creating mind maps. The main idea is centrally placed and examples, details and the like noted in connecting links (Denton et al. 2012, 114-115, using the model designed by Archer et al. 2005). Mind-maps can also be used for representing cause-effect relationships (Denton et al. 2012, 105).

Students may find models of effective summaries helpful. Both good (that is, succinct, with key ideas included, using wording which differs from the original and sits seamlessly in the new textual context) and bad summaries (too lengthy, including irrelevant or incorrect information, too general, comprising a patchwork of words copied from the original) can be provided for students to assess (perhaps as pre-class preparation), perhaps for discussion in tutorials or class blogs. When summaries that students evaluate are relevant to the content currently being taught (as they should be), there will be a double gain of reinforcement of conceptual material as well as skills enhancement.

Another strategy which could help students summarise is the "Know-Want to knowLearned" (K-W-L) process; although designed to assist children when they read (Ogle 1986, $565)$, it can be employed in lectures and/or tutorials. Before class, students are informed of the topic to be covered and asked to provide brief answers to these questions: what I already know about this topic (K); what I want to know (W). After class, they document what was learned (L), framed as a summary of the lesson. A more informal post-class summarising activity is for students to write a summary of the key ideas in text message form (Lewis and Thompson 2010, 3). Research has established that learning will be enhanced in all of these activities if students are given opportunities to discuss their efforts with peers. Discussion can be structured so as to ensure that all students, including EAL students, are engaged. One way is to have students think or write (individually) - pair (discuss with a partner) - share (in the larger group). This is particularly effective in small group teaching but can also be used in lectures. 


\section{PARAPHRASING STRATEGIES}

Paraphrasing is tough for most students, but especially so for L2 students (Kirkland and Saunders 1991, 105). Keck $(2006,272)$ identified a continuum of types of paraphrase, from near copy through to substantial revision. Unsurprisingly, it was found that L2 writers used significantly more near copies than L1 writers. Shi (2008, cited in Hirvela and Du 2013, 90) found that students who lacked confidence would prefer to use direct quotations rather than attempt to paraphrase, or would simply plagiarise. Paraphrasing can be made less problematic if undergraduates understand why it is important and are armed with strategies. A three-step process whereby the information from the original is conveyed differently involves:

Reword: Changing the order of words

This may occur at the level of the sentence or may be the result of combining 2 or more sentences.

Rearrange: Changing the words (using synonyms for non-technical terms)

Elicit or explain why technical terms are not changed.

Recheck: Make sure that your paraphrase conveys the same meaning as the original. ${ }^{7}$

The above strategy works well as an initiation into paraphrasing. Hirvela and Du found that students readily learned the process of "knowledge telling", that is, reproducing what is found in the source; however, there were drawbacks: students "saw no real function for paraphrasing as an academically mediated action" $(2013,92)$. The simple re-wording process encouraged "patchwriting" 8 which limits the writer to working with a narrow range of representations of source material (Bereiter and Scardamalia 1987, 216). Ideally, once the above strategy has been mastered, paraphrasing should be "knowledge transforming" (2013, 92). Good paraphrasing allows for greater flexibility of expression so that the information from source texts is woven into and subordinate to the writer's own argument and writing style $(2013,95)$. Bereiter and Scardamalia (1987, 5-6) point out that knowledge transforming means reshaping content and rhetoric (11); it involves problem formulating and problem-solving, evaluating what has already been written and reconciling competing ideas (Bereiter and Scardamalia 1987, 334). Instead of assuming that students will appreciate this, and see this as a desirable skill set (especially if their native languages and cultures place a high value on respectful subservience to knowledge produced by experts), teachers might include time for reflection on the conceptual gains afforded by mastery of more sophisticated paraphrasing skills. 
Teaching of both summarising and paraphrasing skills can be linked to assisting students to take better notes and vice versa. If students make notes about key ideas, showing how pieces of information relate to each other, and include their own responses to such ideas, they will increase their proficiency in paraphrasing. Ideally, students should be aware of the desired cognitive outcomes (Bereiter and Scardamalia 1987, 323) and should understand that paraphrasing strategies are not "neat tricks to make work easier" but rather "ways to extend their mental capabilities [by] thinking more deeply about more things" (Bereiter and Scardamalia 1987, 334). Prescribed readings can be instructive: students might be required to note how established academics paraphrase and the use of different reporting words (such as argues, claims, believes), as well as considering the importance of such reporting verbs in the accurate representation not only of the tone of the original text but also of their attitude to it.

\section{VOCABULARY: THE FOUNDATION FOR SUMMARISING AND PARAPHRASING}

The afore-mentioned techniques will assist students, but inevitably success in summarising and paraphrasing will depend on students' command of vocabulary so that they can put others' ideas into suitable alternative words. Yang, Baba and Cumming (2004) conducted a study with six EFL students. All were frustrated at not having a broad enough vocabulary to use synonyms or express ideas clearly. Many books and papers have been written about vocabulary enrichment in language courses. Here the discussion focuses on ways that lecturers and tutors can facilitate this learning in content-focused classes.

L2 students, like mother tongue English speakers, have to employ several categories of vocabulary. Denton et al. (2012, 124-5, citing Beck, McKeown and Kucan, 2002) discuss three levels of words: content-specific words, i.e. specialised discourse-specific terms; academic words i.e. words which commonly occur across academic subjects; and lastly, basic words. All three will, of necessity, occur in lectures and tutorials. Nation (2001, 189-190) argues that academic vocabulary is a useful learning goal because it is common to diverse academic texts; it makes up a considerable proportion of words in academic discourses; and is generally not as well-known as technical vocabulary. ${ }^{9}$ I see no grounds for disagreement, nonetheless, in this article, I focus principally on discourse-specific terms. Given the fact that discipline-specific terminology is retained in summaries and paraphrases this might seem illogical; it is, however, justified because technical terms are crucial to disciplinary understanding. Writers must know how to use such terms, their variants and collocations appropriately in summaries and paraphrases. Secondly, lecturers and tutors are unlikely to be able to devote time to explicit academic and basic vocabulary extension activities. Content, and associated terminology and skills, have to be prioritised. Thus, in many universities, this task of assisting EAL students use 
academic and basic vocabulary correctly will fall to academic support units which offer nondiscipline specific assistance to EAL students.

\section{DISCIPLINE-SPECIFIC TERMINOLOGY}

Technical terms are high frequency in specialised areas (Nation 2008, 136). Discipline-specific terminology functions to distil or compress meanings (Woodward-Kron 2008, 238) and enables learners "to make meaning and engage with disciplinary knowledge" (Woodward-Kron 2008, 246). Traditionally, students are expected to grasp specialist vocabulary from listening in lectures and from reading prescribed texts; they are then required to demonstrate this knowledge in assignments.

So how can lecturers and tutors increase learning of key vocabulary for L2 students? The first step in promoting vocabulary enrichment is for lecturers and tutors to think not only about the content of each learning encounter (which they do as a matter of course) but also about the level of difficulty key words or concepts are likely to present; concrete words easier to learn than abstract concepts (Waring and Nation 2004, 101); polysemous words or words which sound similar to other familiar words in English or in L1 might present greater challenges. Another crucial step in lesson planning is purposeful consideration of how such terms can be effectively introduced and reinforced in classroom and homework activities. This may not differ markedly from traditional pedagogy; however, what may be distinctive in what I am recommending is a greater weighting of the terminology in which concepts are embedded. Thus lecturers and tutors should identify the most important ideas and the associated vocabulary and not only anticipate the difficulties ESL students might experience but plan how target vocabulary will be explained so that it is understandable to ESL learners.

Teachers need to capitalise on research that shows that knowledge builds on prior knowledge (Anderson 1980, cited in Denton et al. 2012, 128). This means students need to be given opportunities to discuss or write about what they already know. They might submit blog posts or discuss informally in class or create mind maps showing what they know around key terms. This can be part of K-W-L (Ogle 1986) described earlier. Students can be asked to explain target terms to a non-specialist. Lecturers and tutors can post key word question templates and/or abstracts of lectures/tutorials and/or new vocabulary (ideally, no more than 5 words) prior to the class. This would enable students to build knowledge so they are receptive to the lecture. Other in-class strategies might include a "Word Splash" (Denton et al. 2012, 127): students are provided in advance with key terms that will come up in the class and required to come up with one or more questions for each new term.

Content-focused readings and lectures and tutorials provide a meaning-rich context for 
discipline-specific language learning as well as general academic vocabulary. Prescribed readings will promote vocabulary learning, however, Waring and Nation (2004) cite six of a "long list" (101) of studies that show that although some vocabulary is learned from reading in a foreign language, "the returns are somewhat low... about one tenth of target words will be learned" (101-102). "All studies comparing incidental [through reading] with intentional learning show that intentional learning is more efficient and effective; a well-balanced programme must make use of both, as well as use of vocabulary in speaking and writing" (Waring and Nation 2004, 106-107). Students could be guided as to what to look for and how to go about this.

For learning to take place, "readers must be exposed to text that is accessible" (Waring and Nation 2004, 105, citing Laufer-Dvorkin, 1991; Lai, 1993); if text is too difficult, little will be absorbed, especially if known coverage rate is less than 98 per cent (Coxhead, 2006). Henriksen, Albrechtsen, and Haastrup $(2004,138)$ note the strong correlation between vocabulary and reading scores in the L2. And, as noted, there may be many reasons why incidental learning of key terms in lectures is particularly difficult for L2 students.

Ideally, reading, speaking and writing tasks should be scaffolded: for readings, students might look up meanings of key terms, consider word parts (prefixes, roots, suffixes) and list phrases in which the word is used (thus identifying collocations) and discuss and/or summarise the text or paraphrase selected excerpts. ${ }^{10}$ Tutors might suggest ways that context clues can assist inference ${ }^{11}$ and might set reading exercises where the focus is on both language usage as well as information gathering.

Instructional time is, of course, a limited commodity and will have to be exploited to the full if content coverage targets are to be met. However, coverage of content without some deliberate attention to the terms that communicate the concepts runs the risk of providing poor learning outcomes, especially for L2 students. If lecturers and tutors identify the words students most need for the learning that they are currently engaged in, and ensure that the terms - the various forms they can take and their collocations - receive explicit consideration, this is likely to lead not only to better grasp of content but also to improved reading and writing. Collocations are particularly important: knowledge is stored in categories and words are linked in memory to other words (Denton et al. 2012). Thus, when new vocabulary is introduced teachers will find it worthwhile to demonstrate or, even better, ask students to note, how words are connected.

Teachers need to take cognizance of the fact that L2 students have more barriers to processing aural information than L1 auditors. Andrade cites Holmes 2004 study: Chinese students reported lacking discussion skills and listening comprehension in lectures, identifying problems relating to lecturers" "accents, idiomatic styles, humor and choice of examples" 
(2006, 139). It is thus essential for lecturers and tutors to speak clearly and be mindful of pronunciation. Furthermore, they must match the pace of delivery to students' comprehension, avoid culture-specific analogies and slang, and ensure that the vocabulary used in teaching serves to promote understanding, rather than illustrate the depth and breadth of speaker's knowledge of English. And students could be given opportunities to correctly pronounce terms themselves, perhaps noting syllable structure. Laufer notes that vocabulary enrichment occurs more effectively "when learners attend to many details related to a particular word - e.g. pronunciation, meaning, relation with other words" $(2017,6)$.

Assistance with target language will lighten the cognitive load, thereby affording students better opportunities to think about the content. Chamot (2005) defines explicit instruction; it “includes the development of students' awareness of their strategies, teacher modeling of strategic thinking, identifying the strategies by name, providing opportunities for practice and self-evaluation" $(2005,123)$. Of course, few lecturers will be able to devote this level of attention to vocabulary enrichment but tutors may be able to incorporate some elements. Citing more than a dozen studies, Chamot notes that researchers "in both L1 and L2 contexts agree that explicit instruction is far more effective than simply asking students to use one or more strategies and also fosters metacognition, students' ability to understand their own thinking and learning processes" $(2005,123)$.

Word retention is influenced by the number of encounters with words and also "the amount of attention paid to them and the kind of cognitive operations performed with them" (Laufer 2017, 6). Zou (2017) supports the hypothesis proposed by Hulstijn and Laufer (2001) that the degree of student involvement in word learning tasks, referred to as the "involvement load", determines "the retention of word knowledge" (Zou 2017, 55). According to the theory, three factors comprise the load of a task: need (i.e. the motivational dimension) and two cognitive dimensions: search (this includes such activities as dictionary consultation, inferencing and negotiation) and evaluation (this involves comparing and selecting the most suitable meaning or form, or the creation of an original context) (Zou 2017, 55).

Students should be encouraged to look words up. Discipline-specific dictionaries and encyclopaedias (at an appropriate level) can aid vocabulary learning and can be effective preclass preparation or post-class reinforcement of learning. Electronic dictionaries, favoured by a high proportion of students, may have limited use (Coxhead 2006, 64). English-English dictionaries can be valuable, and Coxhead $(2006,65)$ found that looking up a word then using it leads to greater retention than just reading does, but students who have not been taught how to use a dictionary might find this more of an obstacle than a tool, especially if there are multiple entries for one word. 
Learning is not a spectator sport (Carroll 2012), and many of the strategies suggested seek to increase active engagement in lectures and tutorials. If, for instance, at the end of the class students are to write a few meaningful sentences about key concepts and target words (Lewis and Thompson 2010, 1). the listening will be more purposeful. An OECD study recommends intranets and discussion forums $(2010,14)$. However, while shy students might engage more readily, such tasks may not address imbalances in access to and ease of use of technology due to socio-economic circumstances and also gender (Belcher 1999; Herring 2000 cited in Casanave 2004, 217).

Translation into the mother tongue can assist vocabulary learning and many students routinely use translation dictionaries. Unfortunately, these are often unreliable and the suggested word/s may not be appropriate for the L2 context (Yang et al. 2004, 26). Paxton (2009) found that translation of key terms into the students' mother tongue in tutorial discussions promoted understanding. The groups comprised students with the same mother tongue and discussions about terminology and the conceptual implications were facilitated by a tutor who was fluent in the students' first language. However, this arrangement is probably not feasible in situations where students have diverse home languages. Furthermore, even if it were possible (or desirable) to split students into mother tongue groups, if expert L2 tutors are not available in each of the languages represented, students who speak minority languages will not be supported to the same extent and will thus, in effect, be discriminated against. There are other problems with this method of tutor and students sharing the same L1, and it is one conceded by Paxton: difficulties arise when there is no equivalent term in mother-tongue (2009, 354). Ultimately, all students will be required to understand key texts in English and use technical terms and concepts meaningfully and correctly. Mother-tongue interventions can only go so far, even where they are implementable.

Student discussion is a powerful learning medium. Sun (2017) found that students made good vocabulary gains: "Without trying to memorize words, students learned vocabulary through mental investment in group discussions and generative activities, leading to their mastery of productive word knowledge" $(2017,96)$. Unsurprisingly, allowing students to test their knowledge of words (in this case, orally), rather than being passive recipients of teaching about target words, results in greater learning. When students are given opportunities to use target language in situations which are relatively free of the penalties which assignments contributing to summative grades might impose, there are fewer disincentives for participation. This is likely to be especially true for ESOL students for whom the "context-reduced" aspect of academic language (Cummins, 1996, cited in Paxton 2009, 348) is likely to create difficulties. 


\section{CONCLUSIONS}

Knowledge of content has to involve learning the discourse and associated communicative skills; rather than favour the former while hoping that the last two occur coincidentally, I have proposed that all are deliberately attended to in teaching. I am advocating teaching strategies that aim to empower L2 students to become effective participants in the academic community: "Since word meanings are embedded in 'the background of assumptions, ideologies, values, beliefs and cultural experiences that comprise the meaning system" (Corson 1995 cited in Yang et al. 2004, 20), people must become familiar with words and their meaning systems to communicate successfully. University educators create new knowledge but also impart knowledge and skills to the next generation of practitioners in the discipline or field. The Organisation for Economic Co-operation and Development Review of quality teaching in higher education, notes that: "Institutions want to be recognised as providers of good quality higher education. They understand that competing on the basis of research only is not sufficient to ensure the reputation of the university. As such, they want to find new ways of demonstrating performance. They respond to students' demand for valuable teaching: students want to ensure that their education will lead to jobs and will give them the skills needed in the society of today and tomorrow. Mobility of students and growth of fees increase the consideration given by students to the quality of the teaching" (Hénard 2010,11). Hénard goes on to concede that it is difficult to demonstrate a "causal link between teaching and learning [...]. Although quality teaching is an influential factor on learning outcomes, it is difficult to isolate (and thereby support) the right factors that most affect learning outcomes" $(2010,13)$. Nonetheless, a strong case can be made for the claim that effective teaching acknowledges and caters for diversity.

It is rare to find a homogenous student group: learning styles, motivation and extent of prior knowledge will differ, as will academic skills and proficiency in formal, disciplinespecific language use. Such diversity will reflect heterogeneous home country populations as well as the growing internationalisation of higher education which has enabled thousands upon thousands of students from non-English speaking countries to undertake English-medium studies. Scheyvens, Wild and Overton $(2003,310)$ argue that, "While the visibility of overseas students within university communities has grown considerably in recent years, there has not always been adequate acknowledgement or exploration of ways of adapting to the needs of a more diverse student population."

One size will not fit all. As Hénard argues: "A quality culture at institutional level can be better achieved through diverse initiatives: the consolidation of bottom-up initiatives, smallsized experiments at course or programme level, replication of success stories, the evaluation 
of quality teaching as a vehicle of discussion, and the participation of technical and administrative staff to provide mediation between academia and students" $(2010,14)$. In some instances, this might mean that faculty training is provided so that "pedagogical adjustments" (Andrade 2006, 150) can be made. I have suggested many ways that pedagogy, in contentfocused settings, can be modified to address some of the needs of EAL students so as to support understanding of discipline-specific vocabulary necessary for the crucial academic skills of summarising and paraphrasing. Teachers will need to cherry-pick from the strategies outlined. Some strategies might be more suitable for use with undergraduates than with postgraduates; some for out-of-class activities and some for use in lectures; some for tutorials; and some might not be practicable at all. All require a commitment on the part of teachers to match teaching to what students already know and to create opportunities for active student involvement in learning.

Teaching does not equate to learning, instead it "may be regarded as providing opportunities for students to learn. It is an interactive process as well as an intentional activity" (Brown and Atkins 2002, 2). For students to learn, the material must be presented in ways which make it accessible. For EAL students, this will mean that lecturers and tutors pay careful attention to key academic skills like summarising and paraphrasing, both of which depend upon students understanding - and being able to use in their own writing - the concepts and the discourses in which they are embedded. It is hard to see how this would not impact positively on students' grades.

There are, however, several questions which arise in relation to this argument. First, we might reasonably ask whether the adoption of teaching strategies aimed at assisting L2 students will impact negatively on L1 students. Of course, the answer will depend on a range of factors, including the skills levels of the L1 students, as well as on the manner in which pedagogical strategies are implemented. Nonetheless, I would argue that the principle of teachers assessing and explicitly addressing students' prior knowledge will benefit all students as will fostering the skills of summarising and paraphrasing by ensuring that methods are made explicit and that students' attention is drawn to key concepts and terms. A second question relates to the expansion of English, about which I spoke earlier. The spread of English is caught up in questions of power (Pennycook 2017; Motha and Lin 2014; Kara 2017). English threatens "other languages, cultures and forms of knowledge" (Pennycook 2017, viii). Acknowledging this means that we also need to take into account "the ways in which English is embedded in local economies of desire" (Pennycook 2017, xi). Non-native speakers of English might be undertaking studies in the medium of English for a great many reasons, one of which is likely to be a desire to do so (Rao 2017, 1000). Thus, assisting L2 students to acquire skills needed to 
succeed in English medium universities cannot be assumed to merely serve to reinforce unequal power distributions. Rather, it can be argued that the adoption of pedagogical practices which seek to minimize the difficulties of L2 students will go some way to reducing inequalities (Pennycook 2017, ix).

\section{NOTES}

1. Some of the differences between L1 and L2 written discourse identified by Hinkel (2004) include the role of the audience, assumptions about the reader's knowledge and expectations, reliance on external knowledge and the need to cite such sources, as well as the obvious differences between writing systems, grammatical structures and vocabulary resources. Yang et al. $(2004,18-20)$ note the difference in conventions in writing between L1 (in this case Japanese and Chinese) and L2: language patterns and logic are different, as are "rhetorical schemata" (20): in L1 ambiguity and beauty of word choice are important.

2. Oxford English Dictionary, s.v., "teaching" and s.v., "learning," accessed November 21, 2018, http://www.oed.com/

3. The approaches are ones that can be employed in content-based classes. Although there are many advantages to language across the curriculum, which makes all subject teachers responsible for furthering students' overall English competencies, rather what I am recommending are deliberate teaching strategies in lectures and tutorials to promote summarising and paraphrasing skills and the discipline-specific language needed for these tasks.

4. A typical outline will state that on completion of the module students should know how to:

- $\quad$ explain key concepts;

- $\quad$ engage in and apply key theoretical concepts;

- demonstrate research skills;

- formulate arguments in appropriately academic writing.

5. In Dornyei's 2005 study it is hypothesised "that if proficiency in the target language is part and parcel of one's ideal or ought-to self, this will serve as a powerful motivator to learn the language because of our psychological desire to reduce the discrepancy between our current and possible future selves" (Dörnyei and Ushioda 2009, 4).

6. In their concluding chapter Dörnyei and Ushioda cite the studies by Al-Shehri; Csize'r and Kormos; MacIntyre, Mackinnon and Clément; Ryan; and Taguchi, Magid and Papi: they "generated statistical evidence that add[s] up to a powerful cumulative validity argument" that "future self-guides are potent motivators" $(2009,351)$.

7. Adapted from Lynette (2014). Similarly, Keck (2006, 265) advocates use of synonyms, replacement of one word function with another, changing word form e.g. noun to adjective.

8. Patchwriting: "copying from a source text then deleting some words, altering grammatical structures, or plugging in one-for-one synonym-substitutes" (Thompson et al. 2013, 101 cite Howard 1992, 233).

9. Both Nation (2008) and Coxhead and Byrd (2007) recommend that students learn the vocabulary of the Academic Word List. Such learning is most effective when part of learning the content of the discipline, with necessary conditions for learning to occur: i.e. right level of difficulty and message-focused (which requires a high level of interest) (Nation 2008, 131). The lists may well be brought to the attention of ESL students, however, it is unlikely that there will be time in lectures and tutorials.

10. Zou (2017) found that of three activities - cloze exercises, writing original sentences with target words, and using words in short essays - acquisition of new vocabulary was best in the last. But, as we have seen, this depends upon several skills. 
11. Henriksen et al. $(2004,138)$ note that vocabulary influences L2 readers' reading abilities, but state that inferencing skills are also important.

\section{REFERENCES}

Anderson, J. R. 1980. Cognitive psychology and its implications. San Francisco, Calif.: W.H. Freeman.

Andrade, M. S. 2006. International students in English-speaking universities: Adjustment factors. Journal of Research in International Education 5(2): 131-154. doi: 10.1177 /1475240906065589 (Accessed 7 December 2017).

Beck, I. L., M. G. McKeown and L. Kucan. 2002. Bringing words to life: Robust vocabulary instruction. New York: Guilford.

Belcher, D. 1997. An argument for nonadversarial argumentation: On the relevance of feminist critique for academic discourse to L2 writing pedagogy. Journal of Second Language Writing 6: 1-21.

Bereiter, C. and M. Scardamalia. 1987. The psychology of written composition. Hillsdale, NJ: Lawrence Erlbaum.

Brown, G. and M. Atkins. 2002. Effective teaching in higher education. (First published in 1988). London, U.K. and New York, N.Y.: Routledge.

Carroll, B. C. 1956. Introduction. In Language, thought, and reality: Selected writings of Benjamin Lee Whorf, ed. B. L. Whorf, 1-34. Cambridge, MA: Technology Press of Massachusetts Institute of Technology.

Carroll, J. 2012. Teaching international students: Strategies for enhancing students' learning. (Powerpoint slides) file://file/UsersJ\$/jec169/Home/My\%20Documents/JEC/conference/Jude\% 20Carroll\%20Talk\%202\%20Strategies\%20for\%20enhancing\%20students\%E2\%80\%99\%20 learning\%200ct\%2012.ppt.pdf (Accessed 6 September 2017).

Casanave, C. P. 2004. Controversies in second language writing: Dilemmas and decisions in research and instruction. Ann Arbor, MI: University of Michigan Press.

Chamot, A. U. 2005. Language learning strategy instruction: Current issues and research. Annual Review of Applied Linguistics 25: 112-130.

Corson, D. 1995. Using English words. Dordrecht, The Netherlands: Kluwer Academic.

Coxhead, A. 2006. Essentials of teaching academic vocabulary. Boston, MA: Howard Mifflin.

Coxhead, A. and P. Byrd. 2007. Preparing writing teachers to teach the vocabulary and grammar of academic prose. Journal of Second Language Writing 16: 129-147.

Cummins, J. 1996. Negotiating identities: Education for empowerment in a diverse society. Toronto, ON: California Association for Bilingual Education.

Dartmouth Institute for Writing and Rhetoric. 2017. Sources and citations at Dartmouth. http://writingspeech.dartmouth.edu/learning/materials/sources-and-citations-dartmouth (Accessed 9 August 2017).

Dearden, J. 2014. English as a medium of instruction - a growing global phenomenon. British Council 2014/E484. https://ora.ox.ac.uk/objects/uuid:4f72cdf8-b2eb-4d41-a785-4a283 bf6caaa (Accessed 1 August 2017).

Denton, C. A., S. Vaughn, J. Wexler, D. Bryan and D. Reed. 2012. Effective instruction for middle school students with reading difficulties: The reading teacher's sourcebook. Baltimore, M.D.: Paul Brookes.

Dörnyei, Z. and E. Ushioda. 2009. Motivation, language identity and the L2 self. Bristol: Channel View Publications. https://ebookcentral.proquest.com

Dörnyei, Z. and E. Ushioda. 2009. Motivation, language identities and the L2 self: Future research directions. In Motivation, language identity and the L2 self, ed. Z. Dörnyei and E. Ushioda, 350356. Bristol: Channel View Publications. 
Eduloan. 2009. South Africa's high university dropout rates: What is behind it? https://www.money web.co.za/archive/south-africas-high-university-dropout-rates/b (Accessed 11 July 2017).

Greasley, P. 2011. Doing essays and assignments: Essential tips for students. London, U.K.: Sage.

Gumede, M. 2017. Universities put focus on high drop-out rate. Business Day. https://www.business live.co.za/bd/national/education/2017-03-28-universities-put-focus-on-high-drop-out-rate (Accessed 14 August 2017).

Hedgcock, J. S. and D. R. Ferris. 2009. Teaching readers of English: Students, texts, and contexts. New York: Routledge.

Hénard, F. 2010. Learning our lesson: Review of quality teaching in higher education. Paris, France: OECD Publishing. http://dx.doi.org/10.1787/9789264079281-en (Accessed 2 September 2017).

Henriksen, B., D. Albrechtsen and K. Haastrup. 2004. The relationship between vocabulary size and reading comprehension in L2. In Angles on the English-speaking world. Vol. 4, ed. D. Albrechtsen, K. Haastrup and B. Henriksen, 129-140. Copenhagen, Denmark: Musuem Tusculanum Press.

Herring, S. C. 2000. Gender differences in CMC: Findings and implications. CPSR Newsletter 18(1): $1-12$

Hinkel, E. 2004. Tense, aspect and the passive voice in L1 and L2 academic texts. Language Teaching Research 8(1): 5-29.

Hirvela, A. and Q. Du. 2013. “Why am I paraphrasing?": Undergraduate ESL writers' engagement with source-based academic writing and reading. Journal of English for Academic Purposes 12: 8798.

Holmes, P. 2004. Negotiating differences in learning and intercultural communication. Business Communication Quarterly 67(3): 294-307.

Howard, R. M. 1992. A plagiarism pentimento. Journal of Teaching Writing 11: 233-245.

Hulstijn, H. and B. Laufer. 2001. Some empirical evidence for the involvement load hypothesis in vocabulary acquisition. Language Learning 51: 539-558.

Huttner-Koros, A. 2015. The hidden bias of science's universal language. The Atlantic. https://www.theatlantic.com/science/archive/2015/08/english-universal-language-scienceresearch/400919/ (Accessed 9 August 2017).

Jia, P. and T. Maloney. 2015. Using predictive modelling to identify students at risk of poor university outcomes. Higher Education 70(1): 127-149.

Kara, H. 2017. Challenging the dominance of English. https://helenkara.com/ 2017/06/27/challengingthe-dominance-of-english/ (Accessed 2 August 2017).

Keck, C. 2006. The use of paraphrase in summary writing: A comparison of L1 and L2 writers. Journal of Second Language Writing 15: 261-278.

Kirkland, M. R. and M. A. P. Saunders. 1991. Maximizing student performance in summary writing: Managing cognitive load. TESOL Quarterly 25(1): 105-121.

Lai, F. 1993. The effect of a summer reading course on reading and writing skills. System 21(1): 87100.

Laufer, B. 2017. From word parts to full texts: Searching for effective methods of vocabulary learning. Language Teaching Research 21(1): 5-11.

Laufer-Dvorkin, B. 1991. Similar lexical forms in interlanguage. Gunter Narr Verlag Tubingen: Tubingen.

Lewis, A. and A. Thompson. 2010. Quick summarizing strategies to use in the classroom. (GreencastleAntrim School District.) http://www.gcasd.org/Downloads/Summarizing_Strategies.pdf (Accessed 9 July 2017).

Lobachev, S. 2008. Top languages in global information production. Partnership: The Canadian Journal of Library and Information Practice and Research 3(2). http://dx.doi.org/ 10.21083/partnership.v3i2.826 (Accessed 10 July 2017). 
Lynette, R. 2014. Teaching kids to paraphrase, step by step. http://minds-in-bloom.com/ teaching-kidsto-paraphrase-step-by-step/ (Accessed 6 August 2017).

Motha, S. and A. Lin. 2014. "Non-coercive rearrangements": Theorizing desire in TESOL. TESOL Quarterly 48(2): 331-359.

Nation, I. S. P. 2001. Learning vocabulary in another language. Cambridge, U.K.: Cambridge University Press.

Nation, I. S. P. 2008. Teaching vocabulary: Strategies and techniques. Boston. M.A.: Cengage Learning.

Ogle, D. 1986. K-W-L: A teaching model that develops active reading of expository text. The Reading Teacher 39: 564-570.

Pather, S. 2015. How to stop high drop out rate of first-year university students. The conversation. https://theconversation.com/how-to-stop-high-drop-out-rate-of-first-year-university-students47879 (Accessed 2 September 2017).

Paxton, M. I. J. 2009. "It's easy to learn when you using your home language but with English you need to start learning language before you get to the concept": Bilingual concept development in an English-medium university in South Africa. Journal of Multilingual and Multicultural Development 30(4): 345-359.

Pennycook, A. 2017. The cultural politics of English as an international language. London, United Kingdom and N.Y., NY: Routledge.

Rao, P. 2017. Learning challenges and preferred pedagogies of international students: A perspective from the USA. International Journal of Educational Management 31(7): 1000-1016.

Scheyvens, R., K. Wild and J. Overton. 2003. International students pursuing postgraduate study in geography: Impediments to their learning experiences. Journal of Geography in Higher Education 27(3): 309-323. DOI:10.1080/0309826032000145070.

Shi, L. 2008. Textual appropriation and citing behaviors of university undergraduates. Applied Linguistics 31: 1-24.

Sun, C-H. 2017. The value of picture-book reading-based collaborative output activities for vocabulary retention. Language Teaching Research 21(1): 96-117.

Tertiary Education Commission of New Zealand. 2017. Education performance data published. http://www/tec/govt.nz/news-and-consultations/education-performance-data-published/ (Accessed 11 August 2017).

Thompson, C., J. Morton and N. Storch. 2013. Where from, who, why and how? A study of the use of sources by first year L2 university students. Journal of English for Academic Purposes 12: 99109.

Thomson, P. 2017. Academic publishing in English. https://patthomson.net/2017/07/06/academicpublishing-in-english/ (Accessed 5 July 2017).

Ushioda, E. 2009. A person-in-context relational view of emergent motivation, self and identity. In Motivation, language identity and the L2 self, ed. Z. Dörnyei and E. Ushioda, 215-228. Bristol: Channel View Publications.

Uys, M., J. van der Walt, R. van den Berg and S. Botha. 2007. English medium of instruction: A situation analysis. South African Journal of Education 27(1): 69-82.

Van Wyk, A. 2014. English-medium education in a multicultural setting: A case in South Africa. IRAL - International Review of Applied Linguistics in Language Teaching 52(2): 205-220.

Van Weijen, D. 2012. The language of (future) scientific communication. Research trends. https://www.researchtrends.com/issue-31-november-2012/the-language-of-future-scientificcommunication/ (Accessed 2 August 2017).

Waring, R. and P. Nation. 2004. Second language reading and incidental vocabulary learning. In Angles on the English-speaking world Vol. 4, ed. D. Albrechtsen, K. Haastrup and B. Henriksen, 97-110. Copenhagen, Denmark: Museum Tusculanum Press. 
Whorf, B. L. 1956. Language, thought, and reality: Selected writings of Benjamin Lee Whorf, editor and Introduction by B. C. Carroll. Cambridge. MA: Technology Press of Massachusetts Institute of Technology.

Woodward-Kron, R. 2008. More than just jargon - the nature and role of specialist language in learning disciplinary knowledge. Journal of English for Academic Purposes 7: 234-249.

Yang, L., K. Baba and A. Cumming. 2004. Activity systems for ESL writing improvement: Case studies of three Chinese and three Japanese adult learners of English. In Angles on the English-speaking world. Vol. 4, ed. D. Albrechtsen, K. Haastrup and B. Henriksen, 13-33. Copenhagen, Denmark: Musuem Tusculanum Press.

Zou, D. 2017. Vocabulary acquisition through cloze exercises, sentence-writing and compositionwriting: Extending the evaluation component of the involvement load hypothesis. Language Teaching Research 21(1): 54-75. 